\title{
Neurological Adverse Effects in Patients of Advanced Colorectal Carcinoma Treated with Different Schedules of FOLFOX
}

\author{
Nusrat Bano, ${ }^{1,2,3}$ Rahila Najam, ${ }^{1}$ and Ahmed Mateen ${ }^{4}$ \\ ${ }^{1}$ Department of Pharmacology, University of Karachi, Karachi 75270, Pakistan \\ ${ }^{2}$ Department of Pharmacy, Jinnah University for Women, Karachi 74600, Pakistan \\ ${ }^{3}$ Ziauddin College of Pharmacy, Ziauddin University, 4/B, Block 6, Shahrah-e-Ghalib, Clifton, Karachi 75600, Pakistan \\ ${ }^{4}$ Karachi Institute of Radiotherapy and Nuclear Medicine (KIRAN), Karachi 75330, Pakistan \\ Correspondence should be addressed to Nusrat Bano; nusratbano@hotmail.com
}

Received 22 May 2013; Revised 25 August 2013; Accepted 26 August 2013

Academic Editor: Vassilios A. Georgoulias

Copyright (c) 2013 Nusrat Bano et al. This is an open access article distributed under the Creative Commons Attribution License, which permits unrestricted use, distribution, and reproduction in any medium, provided the original work is properly cited.

\begin{abstract}
The study is designed to assess the frequency and severity of few dose limiting neurological adverse effects of four different schedules of FOLFOX. Patients with histologically confirmed advanced colorectal carcinoma (CRC) were included in the study. Toxicity was graded according to CTC $v$ 2.0. The frequency of grade 3 and 4 adverse effects was comparatively assessed in each treatment arm. The difference in the pattern of toxicity between the treatment schedule was evaluated. The most frequent adverse symptom of neurological adverse effect was grade 1 paresthesia in the patients treated with FOLFOX4 schedule. Grade 4 peripheral neuropathy was reported in few patients of FOLFOX7 treatment arm. Frequency and onset of neurological adverse effects like paresthesia, dizziness, and hypoesthesia were significantly different $(P<0.05)$, whereas frequency and onset of peripheral neuropathy were highly significant $(P<0.01)$ in each treatment arm of FOLFOX. Peripheral neuropathy was associated with electrolyte imbalance and diabetes in few patients. Frequency of symptoms, for example, paresthesia, is associated with increased number of recurrent exposure to oxaliplatin (increased number of cycles) even at low doses $\left(85 \mathrm{mg} / \mathrm{m}^{2}\right)$, whereas severity of symptoms, for example, peripheral neuropathy, is associated with higher dose $\left(130 \mathrm{mg} / \mathrm{m}^{2}\right)$ after few treatment cycles.
\end{abstract}

\section{Introduction}

Incorporation of Oxaliplatin in 5FU/LV regimen has increased the median overall survival rate and progression free survival in patients of advanced colorectal carcinoma. The most frequent dose limiting toxicity of Oxaliplatin is peripheral neuropathy next to neutropenia. Neurotoxicity of Oxaliplatin is exacerbated as an acute sensory transient response, for example, paresthesia and dysesthesia in hand, feet, and peri oral area [1], which appears during or after exposure to Oxaliplatin. Sensory neurotoxicity with oxaliplatin is progressive, cumulative, and reversible, often manifested as delayed effects (12 to 18 months after discontinuation of the therapy). Peripheral neuropathy is hence regarded as the main "safety concern" for chemotherapy with Oxaliplatin, evident as frequent distal, transient paresthesia within the first few minutes of infusion [2]. The cumulative peripheral sensory neuropathy at the total dose of $\cong 800 \mathrm{mg} / \mathrm{m}^{2}$ requires cessation of therapy [3]. Acute syndrome of neurotoxicity is evident in $1-2 \%$ of patients shortly after the infusion, whereas the chronic syndrome is manifested as a dose limiting toxicity in $12-15 \%$ patients at the cumulative dose of $780-850 \mathrm{mg} / \mathrm{m}^{2}$ [4]. The platinum derivative drugs have molecular affinity for the peripheral nervous system $[5,6]$, and thus, Oxaliplatin induced peripheral neuropathy is due to the damage imparted to the peripheral sensory neurons $[7,8]$, leading to the impairment of peripheral neuronal dysfunction $[9,10]$. Chronic Oxaliplatin treatment causes a decrease in the conduction velocity in the digital and caudal nerves leading to associated decrease in caudal action potential aptitude [11]. Oxaliplatin causes a "decrease in phosphorylated neurofilaments in DRG neurons with concomitant alterations in sensory axon" that leads to decrease in the diameter of DRG neuronal cell bodies and indicates neuronal atrophy [12]. Certain gene polymorphisms 
are identified as predisposing factors for peripheral sensory neuropathy $[13,14]$. The pathology of peripheral neuropathy is difficult to be defined by nerve conduction studies [15]. Oxaliplatin induces a direct effect on the excitation potential of sensory neurons and muscle cells. Gamelin et al. (2007) reported that the key components of oxalate synthesis pathways are associated with neurotoxicity, and a minor haplotype in AGXT was able to predict acute and chronic toxicity [14]. The sensitive axonal excitability technique shows that neuronal sodium channel dysfunction is associated with the etiology of CINP [10]. Table 1 comprises of reported phase II and III studies, showcasing the outcome of interventions employed to manage oxaliplatin induced neurotoxicity.

\section{Patients and Methods}

The study was designed in the Department of Pharmacology, University of Karachi, and was conducted in a leading cancer hospital in Pakistan, following institutional authorization, on the patients being admitted during 2009-2012, following informed patients consent. Inclusion criteria were maintained on the following grounds.

(1) Histologically confirmed advanced colorectal carcinoma.

(2) Adequate blood count before therapy.

(3) Age 20-80 years.

(4) ECOG score of $\leq 3$.

(5) No active gastric ulcer and gastrointestinal bleeding (since a year).

Forty-five patients were initially included, and 38 patients were assessable and evaluable by the end of the study. The general patient characteristics are shown in Table 1. The toxicity was graded according to CTC v2.0 on a scale of 1-5 according to the general grade definition of CTC v2.0. The signs and symptoms clearly associated with the disease and the disease progression are not graded during screening of treatment related toxicity. Similarly, treatment delivery system malfunction is not graded during therapy related toxic screening. The defined parameters of neurological toxicities in this study are taste disturbances, headache, paresthesia, dizziness, insomnia, hypoesthesia, and peripheral neuropathy, which were clinically evaluated after each treatment cycle in each treatment arm. The different combination regimens of oxaliplatin with 5FU/LV (FOLFOX), taken as investigational study protocols, for toxicological screening were as follows, where treatment cycles are repeated after two weeks.

FOLFOX4 Treatment Arm [n = 13 (147 Cycles)]

Oxaliplatin: $85 \mathrm{mg} / \mathrm{m}^{2} \mathrm{IV}$ on day 1 .

5-Fluorouracil: $400 \mathrm{mg} / \mathrm{m}^{2}$ IV bolus, followed by $600 \mathrm{mg} / \mathrm{m}^{2}$ IV continuous infusion for 22 hours on days 1 and 2 .

Leucovorin: $200 \mathrm{mg} / \mathrm{m}^{2} \mathrm{IV}$ on days 1 and 2 as 2 -hour infusion before 5 -fluorouracil.
FOLFOX6 Treatment Arm [ $n=12$ (83 Cycles)]

Oxaliplatin: $100 \mathrm{mg} / \mathrm{m}^{2}$ IV on day 1 .

5-Fluorouracil: $400 \mathrm{mg} / \mathrm{m}^{2}$ IV bolus on day 1, followed by $2400 \mathrm{mg} / \mathrm{m}^{2}$ IV continuous infusion for 46 hours.

Leucovorin: $400 \mathrm{mg} / \mathrm{m}^{2} \mathrm{IV}$ on day 1 as 2 -hour infusion before 5-fluorouracil.

mFOLFOX6 Treatment Arm [ $n=5$ (60 Cycles)]

Oxaliplatin: $100 \mathrm{mg} / \mathrm{m}^{2}$ IV 2 hrs infusion on day 1 .

5-Fluorouracil: $2000 \mathrm{mg} / \mathrm{m}^{2}$ IV continuous infusion on days 1 and 2 for 46 hours.

Leucovorin: $100 \mathrm{mg} / \mathrm{m}^{2} 2 \mathrm{hrs}$ infusion on day 1 .

FOLFOX7 Treatment Arm [ $n=8(57$ Cycles $)]$

Oxaliplatin: $130 \mathrm{mg} / \mathrm{m}^{2}$ IV on day 1.

5-Fluorouracil: $2400 \mathrm{mg} / \mathrm{m}^{2}$ IV continuous infusion on days 1 and 2 for 46 hours.

Leucovorin: $400 \mathrm{mg} / \mathrm{m}^{2}$ IV on day 1 as a 2 -hour infusion before 5 -fluorouracil.

The frequency of grade 3 and grade 4 adverse effects was comparatively assessed with all toxicity grades by paired samples test. Data was analyzed on SPSS version 19, and comparative assessment was made by one way ANOVA test. $P$ value less than 0.05 is considered significant and less than 0.01 is considered highly significant, whereas a value less than 0.001 is considered very highly significant.

\section{Results}

The most severe symptom reported was peripheral neuropathy $13 \%$ grade 2 and $8 \%$ grade 3 , in patients of FOLFOX 4 (Figure 1). The most severe grade of symptoms was grade 3 , and the only symptom reported with severity of grade 3 was $4 \%$ peripheral neuropathy (Figure 2). The most severe symptom reported in patients of mFOLFOX6 treatment arm is $13 \%$ grade 2 peripheral neuropathy. There was no grade 3 or 4 neurological toxicity in patients of mFOLFOX6 arm. The incidence rate of each adverse effect and the severity of the symptoms with related frequency are shown in Figure 3. The most severe symptom reported in patients of FOLFOX7 treatment arm is grade 3 peripheral neuropathy in $11 \%$ patients and $2 \%$ grade 4 peripheral neuropathy (Figure 4 ). The difference between the incidence rate of grade 1 and 2 toxicity and grade 3 toxicity of all parameters in neurological toxicity is very highly significant $(P<0.001)$. The difference between grade 3 neurological toxicity with all grades of toxicity is shown in Table 2 . The difference between the incidence rate of grade 4 toxicity with all grades of toxicity for each parameters of neurological toxicity is highly significant $(P<0.001)$. The difference between grade 4 neurological toxicity with all grades of toxicity is shown in Table 3. There was no difference in the incidence rate of adverse effects like headache and insomnia between the different schedules of FOLFOX. The frequency and onset 
TABLE 1: Management of oxaliplatin induced neurotoxicity comprising of phase II and phase III studies.

\begin{tabular}{|c|c|c|c|c|c|}
\hline Study & Year & Patient type & Treatment type & Intervention & Outcome \\
\hline $\begin{array}{l}\text { Wen et al. } \\
{[16]}\end{array}$ & 2013 & $\begin{array}{l}\text { Colorectal cancer } \\
(N=1170)\end{array}$ & $\begin{array}{l}\text { Oxaliplatin based } \\
\text { chemotherapy }\end{array}$ & $\mathrm{Ca} / \mathrm{Mg}$ infusion & $\begin{array}{l}\text { Reduction in grade } 3 \text { acute } \\
\text { neurotoxicity }\end{array}$ \\
\hline Xu et al. [17] & 2013 & $\begin{array}{l}\text { Gastrointestinal cancer } \\
(N=1765)\end{array}$ & $\begin{array}{l}\text { Oxaliplatin based } \\
\text { chemotherapy }\end{array}$ & $\mathrm{Ca} / \mathrm{Mg}$ infusion & $\begin{array}{l}\text { Reduction in grade } 1 \text { and } 2 \text { and } \\
\text { no effect on grade } 3 \text { neurotoxicity }\end{array}$ \\
\hline $\begin{array}{l}\text { Grothey et al. } \\
{[18]}\end{array}$ & 2013 & Colon cancer $(N=353)$ & FOLFOX & $\mathrm{Ca} / \mathrm{Mg}$ infusion & $\begin{array}{l}\text { No reduction in cumulative } \\
\text { sensory neurotoxicity }\end{array}$ \\
\hline $\begin{array}{l}\text { Gobran and } \\
\text { Nagy [19] }\end{array}$ & 2013 & $\begin{array}{l}\text { Colorectal cancer } \\
(N=60)\end{array}$ & $\begin{array}{l}\text { Oxaliplatin based } \\
\text { chemotherapy }\end{array}$ & $\mathrm{Ca} / \mathrm{Mg}$ infusion & $\begin{array}{l}\text { Significant reduction in } \\
\text { chemotherapy induced } \\
\text { neuropathy }\end{array}$ \\
\hline $\begin{array}{l}\text { de Afonseca } \\
\text { et al. [20] }\end{array}$ & 2013 & $\begin{array}{l}\text { Colorectal and gastric } \\
\text { cancer }(N=34)\end{array}$ & $\begin{array}{l}\text { Oxaliplatin based } \\
\text { chemotherapy }\end{array}$ & Vitamin E & $\begin{array}{l}\text { No reduction in chemotherapy } \\
\text { induced neuropathy }\end{array}$ \\
\hline $\begin{array}{l}\text { Grothey et al. } \\
{[21]}\end{array}$ & 2011 & Colon cancer $(N=102)$ & $\begin{array}{l}\text { Oxaliplatin, } 5 \mathrm{FU} \text {, and } \\
\text { leucovorin }\end{array}$ & $\mathrm{Ca} / \mathrm{Mg}$ infusion & $\begin{array}{l}\text { No effect in cold induced sensory } \\
\text { neuropathy } \\
\text { Effective neuroprotective effect } \\
\text { of } \mathrm{Ca} / \mathrm{Mg} \text { therapy in oxaliplatin } \\
\text { induced peripheral neuropathy }\end{array}$ \\
\hline $\begin{array}{l}\text { Knijn et al. } \\
{[22]}\end{array}$ & 2011 & $\begin{array}{l}\text { Advanced colon cancer } \\
(N=732)\end{array}$ & $\begin{array}{l}\text { Capecitabine, } \\
\text { oxaliplatin, and } \\
\text { bevacizumab with and } \\
\text { without cetuximab }\end{array}$ & $\mathrm{Ca} / \mathrm{Mg}$ infusion & $\begin{array}{l}\text { Significant reduction in } \\
\text { chemotherapy induced } \\
\text { neuropathy }\end{array}$ \\
\hline $\begin{array}{l}\text { Kottschade et } \\
\text { al. [23] }\end{array}$ & 2011 & Not specified $(N=207)$ & $\begin{array}{l}\text { Taxanes, cisplatin, } \\
\text { oxaliplatin, and } \\
\text { carboplatin based } \\
\text { chemotherapy }\end{array}$ & Vitamin E & $\begin{array}{l}\text { No significant reduction in } \\
\text { chemotherapy induced } \\
\text { neuropathy }\end{array}$ \\
\hline $\begin{array}{l}\text { Ishibashi et } \\
\text { al. [24] }\end{array}$ & 2010 & $\begin{array}{l}\text { Metastatic colorectal } \\
\text { cancer }(N=33)\end{array}$ & FOLFOX6 & $\mathrm{Ca} / \mathrm{Mg}$ infusion & $\begin{array}{l}\text { No significant reduction in } \\
\text { chemotherapy induced } \\
\text { neuropathy }\end{array}$ \\
\hline $\begin{array}{l}\text { Chay et al. } \\
{[25]}\end{array}$ & 2010 & $\begin{array}{l}\text { Colorectal cancer } \\
(N=27)\end{array}$ & $\begin{array}{l}\text { FOLFOX4/ Capecitabine } \\
\text { + oxaliplatin }\end{array}$ & $\mathrm{Ca} / \mathrm{Mg}$ infusion & $\begin{array}{l}\text { No significant reduction in } \\
\text { chemotherapy induced } \\
\text { neuropathy }\end{array}$ \\
\hline $\begin{array}{l}\text { Gamelin et al. } \\
{[26]}\end{array}$ & 2004 & $\begin{array}{l}\text { Colorectal cancer } \\
(N=161)\end{array}$ & $\begin{array}{l}\text { Oxaliplatin based } \\
\text { chemotherapy }\end{array}$ & $\mathrm{Ca} / \mathrm{Mg}$ infusion & $\begin{array}{l}\text { Low frequency of grade } 3 \text { distal } \\
\text { paresthesia in } \mathrm{Ca} / \mathrm{Mg} \text { group } \\
\text { No case of pseudolaryngospasm } \\
\text { in } \mathrm{Ca} / \mathrm{Mg} \text { group }\end{array}$ \\
\hline
\end{tabular}

of neurological toxic symptoms like paresthesia, dizziness, and hypoesthesia $(P<0.05)$ were significantly different, and peripheral neuropathy $(P<0.01)$ was highly significantly different in each treatment arm of FOLFOX (Table 4).

\section{Discussion}

Peripheral neuropathy is more frequently reported in patients of FOLFOX7 and mFOLFOX6 treatment arms as compared to FOLFOX6 and FOLFOX4 treatment arms. Chemotherapy induced peripheral neuropathy with nociceptive sensory loss during treatment was a very painful condition in some of our patients, although the association between the pain and the loss of sensation is not verified $[27,28]$. The most frequent neurological adverse effect reported in the patients of FOLFOX4 is grade 1 paresthesia. Cold sensitive muscle contractions of the jaw and extremities were observed in few patients, giving way to sensory ataxia towards the end of the therapy. Hyponatremia was also assessed in these patients.
The most frequent adverse neurological symptom reported in the patients of FOLFOX6 treatment arm was grade 1 taste disturbance ( 39 cases) followed by headache ( 28 cases), whereas the least frequently reported neurological adverse event was insomnia (7 cases). Grade 4 neurological toxicity was not reported in any patient of FOLFOX6 treatment arm. Female patients treated with FOLFOX6 are more prone to risk of peripheral neuropathy and hypoaesthesia. Patients, presented with grade 3 peripheral neuropathy were treated with electrolyte reimbursement who with positive outcome manifesting as reduction in severity of the symptom. The symptoms of CIPN (chemotherapy induced peripheral neuropathy) were also significantly reduced by individualized treatment with calcium/magnesium $(\mathrm{Ca} / \mathrm{Mg})$ infusion and vitamin $\mathrm{E}$.

Most frequent adverse symptom of neurological toxicity reported in the patients treated with mFOLFOX was mild taste disturbances (42 cases) at different stages during the course of treatment. Grade 2 hypoesthesia was reported in $7 \%$ patients of FOLFOX6 treatment arm. Headache was 
Table 2: Patient characteristics.

\begin{tabular}{|c|c|c|c|c|c|c|c|c|}
\hline \multirow{2}{*}{ Parameters } & \multicolumn{2}{|c|}{ FOLFOX4 } & \multicolumn{2}{|c|}{ FOLFOX6 } & \multicolumn{2}{|c|}{ mFOLFOX6 } & \multicolumn{2}{|c|}{ FOLFOX7 } \\
\hline & No. of patients & $\%$ & No. of patients & $\%$ & No. of patients & $\%$ & No. of patients & $\%$ \\
\hline \multicolumn{9}{|l|}{ Gender } \\
\hline Male & 10 & 76.92 & 9 & 75 & 4 & 80 & 6 & 75 \\
\hline Female & 3 & 23.08 & 3 & 25 & 1 & 20 & 2 & 25 \\
\hline \multicolumn{9}{|l|}{ Age: year } \\
\hline Median & 63 & & 60 & & 51 & & 67 & \\
\hline Range & $58-64$ & & $52-68$ & & $47-53$ & & $49-72$ & \\
\hline \multicolumn{9}{|c|}{ ECOG performance status } \\
\hline 0 & 1 & 7.69 & 1 & 8.33 & 0 & 0 & 0 & 0 \\
\hline 1 & 4 & 30.77 & 1 & 8.33 & 3 & 60 & 2 & 25 \\
\hline 2 & 7 & 53.85 & 10 & 83.33 & 2 & 40 & 5 & 62.5 \\
\hline 3 & 1 & 7.69 & 0 & 0 & 0 & 0 & 1 & 12.5 \\
\hline \multicolumn{9}{|l|}{ Primary site } \\
\hline Colon & 10 & 76.92 & 7 & 58.33 & 2 & 40 & 3 & 37.5 \\
\hline Rectum & 3 & 23.08 & 5 & 41.67 & 1 & 20 & 2 & 25 \\
\hline Multiple & 0 & 0 & 0 & 0 & 2 & 40 & 3 & 37.5 \\
\hline \multicolumn{9}{|l|}{ No. of sites } \\
\hline 1 & 7 & 53.85 & 4 & 33.33 & 3 & 60 & 6 & 75 \\
\hline$\geq 2$ & 6 & 46.15 & 8 & 66.67 & 2 & 40 & 2 & 25 \\
\hline \multicolumn{9}{|l|}{ AlkPO4 } \\
\hline Normal & 3 & 23.08 & 6 & 50 & 3 & 60 & 5 & 62.5 \\
\hline Increased & 7 & 53.85 & 3 & 25 & 2 & 40 & 3 & 37.5 \\
\hline Unknown & 3 & 23.08 & 3 & 25 & 0 & 0 & 0 & 0 \\
\hline
\end{tabular}

TABLE 3: Comparative differences in frequency of grade 3 neurological adverse effects with grade 1 and grade 2 adverse effects.

\begin{tabular}{|c|c|c|c|c|c|c|}
\hline \multicolumn{7}{|c|}{ Paired samples test } \\
\hline Toxicity & Mean & Std. deviation & Mean difference & $t$ & df & $P$ value \\
\hline Taste disturbance grade 1,2 & 3.816 & 3.525 & \multirow{2}{*}{3.789} & \multirow{2}{*}{6.608} & \multirow{2}{*}{37.000} & \multirow{2}{*}{0.000} \\
\hline Taste disturbance grade 3 & 0.026 & 0.162 & & & & \\
\hline Headache grade 1,2 & 2.053 & 2.588 & \multirow{2}{*}{2.053} & \multirow{2}{*}{4.888} & \multirow{2}{*}{37.000} & \multirow{2}{*}{0.000} \\
\hline Headache grade 3 & 0.000 & 0.000 & & & & \\
\hline Paresthesia grade 1,2 & 5.079 & 3.529 & \multirow{2}{*}{5.079} & \multirow{2}{*}{8.872} & \multirow{2}{*}{37.000} & \multirow{2}{*}{0.000} \\
\hline Paresthesia grade 3 & 0.000 & 0.000 & & & & \\
\hline Dizziness grade 1,2 & 1.474 & 2.345 & \multirow{2}{*}{1.474} & \multirow{2}{*}{3.874} & \multirow{2}{*}{37.000} & \multirow{2}{*}{0.000} \\
\hline Dizziness grade 3 & 0.000 & 0.000 & & & & \\
\hline Insomnia grade 1,2 & 1.474 & 2.357 & \multirow{2}{*}{1.474} & \multirow{2}{*}{3.855} & \multirow{2}{*}{37.000} & \multirow{2}{*}{0.000} \\
\hline Insomnia grade 3 & 0.000 & 0.000 & & & & \\
\hline Peripheral neuropathy grade 1,2 & 4.947 & 3.385 & \multirow{2}{*}{4.395} & \multirow{2}{*}{7.045} & \multirow{2}{*}{37.000} & \multirow{2}{*}{0.000} \\
\hline Peripheral neuropathy grade 3 & 0.553 & 1.589 & & & & \\
\hline Hypoaesthesia grade 1,2 & 4.526 & 4.105 & \multirow{2}{*}{4.526} & \multirow{2}{*}{6.797} & \multirow{2}{*}{37.000} & \multirow{2}{*}{0.000} \\
\hline Hypoaesthesia grade 3 & 0.000 & 0.000 & & & & \\
\hline
\end{tabular}

$P$ value $<0.05$ (significant), $P$ value $<0.01$ (highly significant), and $P$ value $<0.001$ (very highly significant).

a mild and less frequent symptom (17\%) in mFOLFOX6 patients, whereas peripheral neuropathy, hypoesthesia, and paresthesia were the most frequently reported neurological toxicity in the patients.

It is important to assess the neurological toxicities in these patients as a delayed toxic effect during followup since the platinum compounds are unique in the sense that they produce ganglionopathy, and the progression of sensory loss may progress even after the cessation of therapy over months referred to as "coating" [28]. The patients experiencing CIPN have no signs of axonal degeneration shown by nerve biopsy study or neurophysiological exams $[29,30]$. Glutathione is also shown to be effective in reducing the symptoms of CIPN, whereas agents like topical pain 
TABLE 4: Comparative differences in frequency of grade 4 neurological adverse effects with all grades of toxicity.

\begin{tabular}{|c|c|c|c|c|c|c|}
\hline \multicolumn{7}{|c|}{ Paired samples test } \\
\hline Toxicity & Mean & Std. deviation & Mean difference & $t$ & df & $P$ value \\
\hline Taste disturbance grade 1,2 , and 3 & 3.842 & 3.522 & \multirow{2}{*}{3.842} & \multirow{2}{*}{6.724} & \multirow{2}{*}{37.000} & \multirow{2}{*}{0.000} \\
\hline Taste disturbance grade 4 & 0.000 & 0.000 & & & & \\
\hline Headache grade 1,2 , and 3 & 2.053 & 2.588 & \multirow{2}{*}{2.053} & \multirow{2}{*}{4.888} & \multirow{2}{*}{37.000} & \multirow{2}{*}{0.000} \\
\hline Headache grade 4 & 0.000 & 0.000 & & & & \\
\hline Paresthesia grade 1,2 , and 3 & 5.079 & 3.529 & \multirow{2}{*}{5.079} & \multirow{2}{*}{8.872} & \multirow{2}{*}{37.000} & \multirow{2}{*}{0.000} \\
\hline Paresthesia grade 4 & 0.000 & 0.000 & & & & \\
\hline Dizziness grade 1,2 , and 3 & 1.474 & 2.345 & \multirow{2}{*}{1.474} & \multirow{2}{*}{3.874} & \multirow{2}{*}{37.000} & \multirow{2}{*}{0.000} \\
\hline Dizziness grade 4 & 0.000 & 0.000 & & & & \\
\hline Insomnia grade 1,2 , and 3 & 1.474 & 2.357 & \multirow{2}{*}{1.474} & \multirow{2}{*}{3.855} & \multirow{2}{*}{37.000} & \multirow{2}{*}{0.000} \\
\hline Insomnia grade 4 & 0.000 & 0.000 & & & & \\
\hline Peripheral neuropathy grade 1,2 , and 3 & 5.500 & 3.630 & \multirow{2}{*}{5.474} & \multirow{2}{*}{9.277} & \multirow{2}{*}{37.000} & \multirow{2}{*}{0.000} \\
\hline Peripheral neuropathy grade 4 & 0.026 & 0.162 & & & & \\
\hline Hypoaesthesia grade 1,2 , and 3 & 4.526 & 4.105 & \multirow{2}{*}{4.526} & \multirow{2}{*}{6.797} & \multirow{2}{*}{37.000} & \multirow{2}{*}{0.000} \\
\hline Hypoaesthesia Grade 4 & 0.000 & 0.000 & & & & \\
\hline
\end{tabular}

$P$ value $<0.05$ (significant), $P$ value $<0.01$ (highly significant), and $P$ value $<0.001$ (very highly significant).

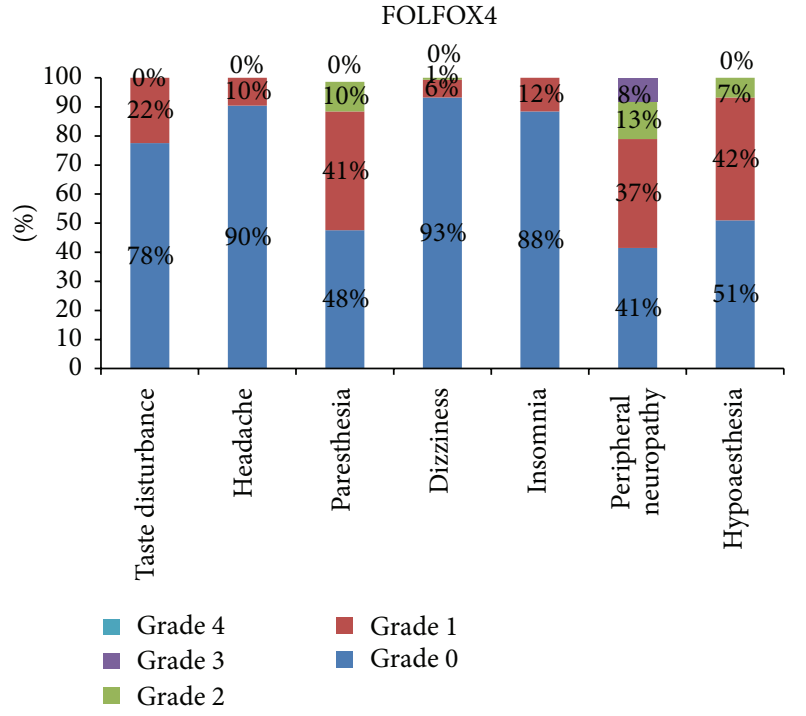

FIGURE 1: Percentage frequency of neurological adverse effects of all toxicity grades in FOLFOX4 treatment arm.

relievers (baclofen/amitriptyline/ketamine gel) and serotonin and norepinephrine reuptake inhibitors (venlafaxine and duloxetine) also have proven efficacy against CIPN [31].

The most frequent symptom of neurotoxicity reported in the patients included in FOLFOX7 treatment arm was grade 1 hypoaesthesia (36 cases). Grade 4 peripheral neuropathy was reported only in FOLFOX7 treatment arm, and although the incidence rate of grade 4 peripheral neuropathy was low, but the treatment was delayed and doses of Oxaliplatin reduced to one and then two levels in the patient. Persistence of severity of the symptom required discontinuation of treatment. One of these patients was treated for tuberculosis in the past and was since suffering from previous treatment induced neurological symptoms. There were only few cases of grade

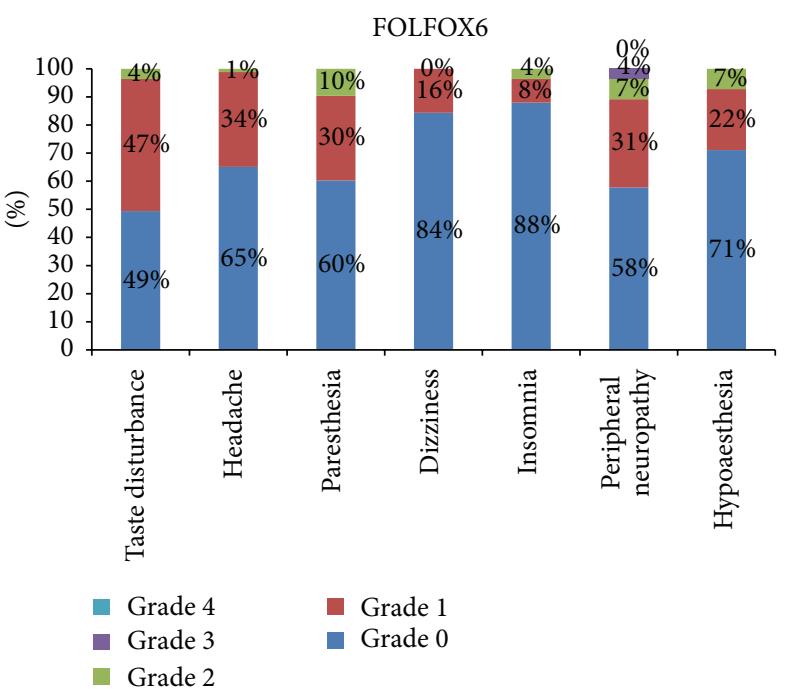

FIGURE 2: Percentage frequency of neurological adverse effects of all toxicity grades in FOLFOX6 treatment arm.

3 peripheral neuropathy and taste disturbances; however, the overall difference between the incidence rate of grade 3 toxicity and grade 1 and 2 toxicity was very highly significant. Grade 4 peripheral neuropathy was reported in FOLFOX7 only. Toxic neuropathy can occur in patients who have preexisting neuropathological disorder such as underlying inherited or inflammatory neuropathies. The selection of a specific schedule of FOLFOX to minimize the risk of symptoms like paresthesia, hypoesthesia, and dizziness is important as the patterns of these toxicities are variable in different schedules of treatment. Severity and frequency of peripheral neuropathy can be carefully avoided by selecting regimens with less toxic neurological manifestations using mFOLFOX6. Our observations during this study support that 


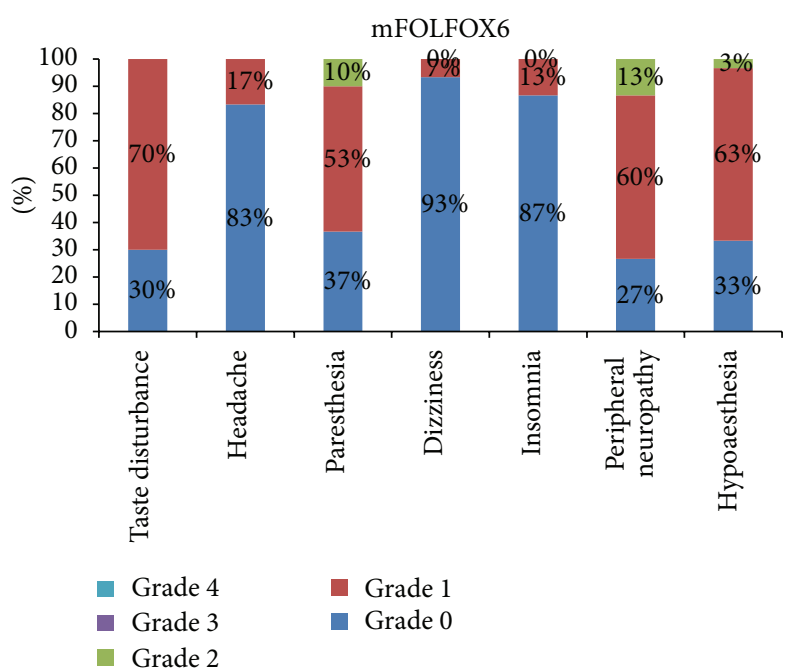

FIGURE 3: Percentage frequency of neurological adverse effects of all toxicity grades in mFOLFOX6 treatment arm.

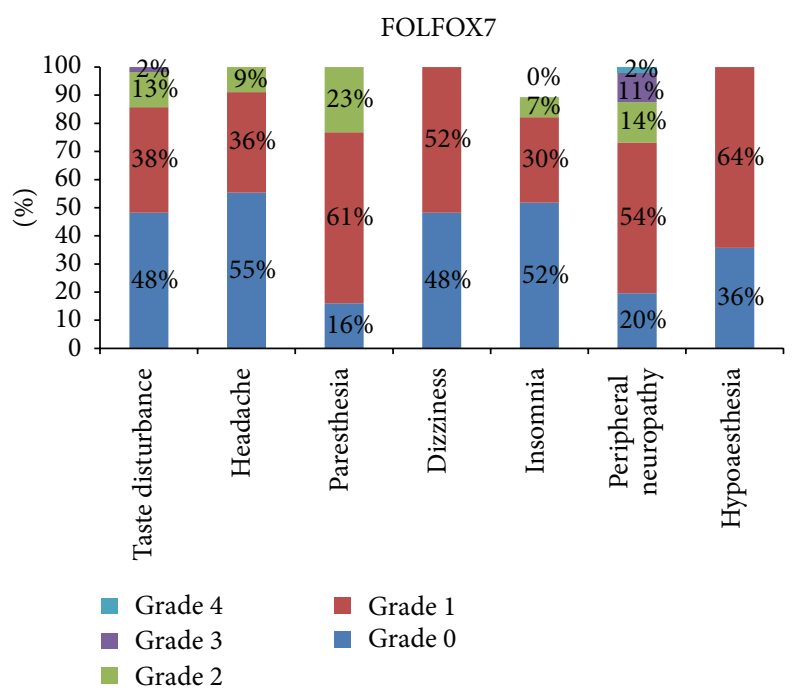

FIGURE 4: Percentage frequency of neurological adverse effects of all toxicity grades in FOLFOX7 treatment arm.

pretreatment of hypomagnesaemia and anemia conversely associated with age can be identified as predictors of neurotoxicity in oxaliplatin based treatment [32]. Although the use of nutraceuticals, that is, vitamin E, Vitamin B6 and calcium as prophylactic or pretreatment agents for the management of oxaliplatin induced peripheral neuropathy is not well established [33]; few of our patients responded positively to them. A detailed and comprehensive study is further required to confirm the effective and undisputed protocol for the management of oxaliplatin induced neurotoxicity.

\section{Conclusion}

Grade 4 peripheral neuropathy with nociceptive sensory loss was a painful complication reported in a patient in
TABLE 5: Comparative differences in incidence rate of neurological adverse effects between each treatment arm of FOLFOX.

\begin{tabular}{lcc}
\hline & ANOVA & \\
Toxicity & $F$ & $P$ value \\
\hline Neurological & & \\
Taste disturbance & 4.370 & 0.010 \\
Headache & 1.169 & 0.336 \\
Paresthesia & 3.475 & 0.026 \\
Dizziness & 3.458 & 0.027 \\
Insomnia & 0.955 & 0.425 \\
Peripheral neuropathy & 5.077 & 0.005 \\
Hypoaesthesia & 3.598 & 0.023 \\
\hline
\end{tabular}

$P$ value $<0.05$ (significant), $P$ value $<0.01$ (highly significant), and $P$ value $<$ 0.001 (very highly significant).

FOLFOX7. Grade 3 peripheral neuropathy was reported in all other schedules of FOLFOX except in the patients treated with modified schedule of FOLFOX6. The incidence rate of paresthesia was higher in schedules with increased number of treatment cycles despite lower dose of Oxaliplatin.

\section{Conflict of Interests}

The authors declare no conflict of interests.

\section{Authors' Contribution}

Nusrat Bano contributed in the conception and design of the study, acquisition of data, and analysis and interpretation of the data. Rahila Najam contributed in the supervision of the research, interpretation of findings, and final approval of the research. Ahmed Mateen contributed in the clinical assessment, interpretation of findings, and final approval of the research.

\section{References}

[1] E. Raymond, R. Lawrence, E. Izbicka, S. Faivre, and D. D. Von Hoff, "Activity of oxaliplatin against human tumor colonyforming units," Clinical Cancer Research, vol. 4, no. 4, pp. 10211029,1998

[2] T. André, C. Boni, L. Mounedji-Boudiaf et al., "Oxaliplatin, fluorouracil, and leucovorin as adjuvant treatment for colon cancer," The New England Journal of Medicine, vol. 350, no. 23, pp. 2343-2351, 2004.

[3] D. Simpson, C. Dunn, M. Curran, and K. L. Goa, "Oxaliplatin: a review of its use in combination therapy for advanced metastatic colorectal cancer," Drugs, vol. 63, no. 19, pp. 2127-2156, 2003.

[4] M. W. Saif and J. Reardon, "Management of oxaliplatin-induced peripheral neuropathy," Therapeutic and Clinical Risk Management, vol. 1, no. 4, pp. 249-258, 2005.

[5] E. S. McDonald, K. R. Randon, A. Knight, and A. J. Windebank, "Cisplatin preferentially binds to DNA in dorsal root ganglion neurons in vitro and in vivo: a potential mechanism for neurotoxicity," Neurobiology of Disease, vol. 18, no. 2, pp. 305313, 2005. 
[6] A. A. Argyriou, P. Polychronopoulos, G. Iconomou et al., "Incidence and characteristics of peripheral neuropathy during oxaliplatin-based chemotherapy for metastatic colon cancer," Acta Oncologica, vol. 46, no. 8, pp. 1131-1137, 2007.

[7] G. Cavaletti, G. Tredici, M. G. Petruccioli et al., "Effects of different schedules of oxaliplatin treatment on the peripheral nervous system of the rat," European Journal of Cancer, vol. 37, no. 18, pp. 2457-2463, 2001.

[8] A. Binder, M. Stengel, R. Maag et al., "Pain in oxaliplatininduced neuropathy-sensitisation in the peripheral and central nociceptive system," European Journal of Cancer, vol. 43, no. 18, pp. 2658-2663, 2007.

[9] S. B. Park, C. S.-Y. Lin, A. V. Krishnan, D. Goldstein, M. L. Friedlander, and M. C. Kiernan, "Oxaliplatin-induced neurotoxicity: changes in axonal excitability precede development of neuropathy," Brain, vol. 132, no. 10, pp. 2712-2723, 2009.

[10] M. C. Kiernan, S. B. Park, D. Goldstein, C. S.-Y. Lin, A. V. Krishnan, and M. L. Friedlander, "Acute abnormalities of sensory nerve function associated with oxaliplatin-induced neurotoxicity," Journal of Clinical Oncology, vol. 27, no. 8, pp. 1243-1249, 2009.

[11] C. L. Renn, V. A. Carozzi, P. Rhee, D. Gallop, S. G. Dorsey, and G. Cavaletti, "Multimodal assessment of painful peripheral neuropathy induced by chronic oxaliplatin-based chemotherapy in mice," Molecular Pain, vol. 7, article 29, 2011.

[12] S. M. F. Jamieson, J. Subramaniam, J. J. Liu et al., "Oxaliplatininduced loss of phosphorylated heavy neurofilament subunit neuronal immunoreactivity in rat DRG tissue," Molecular Pain, vol. 5, article 66, 2009.

[13] T. Lecomte, B. Landi, P. Beaune, P. Laurent-Puig, and M.-A. Loriot, "Glutathione S-transferase P1 polymorphism (Ile105Val) predicts cumulative neuropathy in patients receiving oxaliplatin-based chemotherapy," Clinical Cancer Research, vol. 12, no. 10, pp. 3050-3056, 2006.

[14] L. Gamelin, O. Capitain, A. Morel et al., "Predictive factors of oxaliplatin neurotoxicity: the involvement of the oxalate outcome pathway," Clinical Cancer Research, vol. 13, no. 21, pp. 6359-6368, 2007.

[15] M. C. Kiernan and A. V. Krishnan, "The pathophysiology of oxaliplatin-induced neurotoxicity," Current Medicinal Chemistry, vol. 13, no. 24, pp. 2901-2907, 2006.

[16] F. Wen, Y. Zhou, W. Wang et al., "Ca/Mg infusions for the prevention of oxaliplatin-related neurotoxicity in patients with colorectal cancer: a meta-analysis," Annals of Oncology, vol. 24, no. 1, pp. 171-178, 2013.

[17] X. T. Xu, Z. H. Dai, Q. Xu et al., "Safety and efficacy of calcium and magnesium infusions in the chemoprevention of oxaliplatin-induced sensory neuropathy in gastrointestinal cancers," Journal of Digestive Diseases, vol. 14, no. 6, pp. 288298, 2013.

[18] A. Grothey, Q. Rui, D. Shaker et al., "o-0032 phase III randomized, placebo (pl)-controlled, double-blind study of intravenous calcium/magnesium (camg) to prevent oxaliplatin-induced sensory neurotoxicity (snt), n08cb: an alliance for clinical trials in oncology studyl," Annals of Oncology, vol. 24, supplement 4, Article ID iv24, 2013.

[19] Gobran and S. Nagy, "Role of calcium and magnesium infusion in prevention of oxaliplatin neurotoxicity. A phase III trial," The Chinese-German Journal of Clinical Oncology, vol. 12, no. 5, pp. 232-236, 2013.

[20] de Afonseca, O. Samuel, M. C. Felipe et al., "Vitamin E for prevention of oxaliplatin-induced peripheral neuropathy: a pilot randomized clinical trial," Sao Paulo Medical Journal, vol. 131, no. 1, pp. 35-38, 2013.

[21] A. Grothey, D. A. Nikcevich, J. A. Sloan et al., "Intravenous calcium and magnesium for oxaliplatin-induced sensory neurotoxicity in adjuvant colon cancer: NCCTG N04C7," Journal of Clinical Oncology, vol. 29, no. 4, pp. 421-427, 2011.

[22] N. Knijn, J. Tol, M. Koopman et al., "The effect of prophylactic calcium and magnesium infusions on the incidence of neurotoxicity and clinical outcome of oxaliplatin-based systemic treatment in advanced colorectal cancer patients," European Journal of Cancer, vol. 47, no. 3, pp. 369-374, 2011.

[23] L. A. Kottschade, J. A. Sloan, M. A. Mazurczak et al., "The use of vitamin $\mathrm{E}$ for the prevention of chemotherapy-induced peripheral neuropathy: results of a randomized phase III clinical trial," Supportive Care in Cancer, vol. 19, no. 11, pp. 1769-1777, 2011.

[24] K. Ishibashi, N. Okada, T. Miyazaki, M. Sano, and H. Ishida, "Effect of calcium and magnesium on neurotoxicity and blood platinum concentrations in patients receiving mFOLFOX6 therapy: a prospective randomized study," International Journal of Clinical Oncology, vol. 15, no. 1, pp. 82-87, 2010.

[25] W.-Y. Chay, S.-H. Tan, Y.-L. Lo et al., "Use of calcium and magnesium infusions in prevention of oxaliplatin induced sensory neuropathy," Asia-Pacific Journal of Clinical Oncology, vol. 6, no. 4, pp. 270-277, 2010.

[26] L. Gamelin, M. Boisdron-Celle, R. Delva et al., "Prevention of oxaliplatin-related neurotoxicity by calcium and magnesium infusions: a retrospective study of 161 patients receiving oxaliplatin combined with 5-fluorouracil and leucovorin for advanced colorectal cancer," Clinical Cancer Research, vol. 10, no. 12, pp. 4055-4061, 2004.

[27] S. Wolf, D. Barton, L. Kottschade, A. Grothey, and C. Loprinzi, "Chemotherapy-induced peripheral neuropathy: prevention and treatment strategies," European Journal of Cancer, vol. 44, no. 11, pp. 1507-1515, 2008.

[28] A. J. Windebank and W. Grisold, "Chemotherapy-induced neuropathy," Journal of the Peripheral Nervous System, vol. 13, no. 1, pp. 27-46, 2008.

[29] J. Graham, M. Muhsin, and P. Kirkpatrick, "Oxaliplatin. Market analysis," Nature Reviews Drug Discovery, vol. 3, no. 1, pp. 11-12, 2004.

[30] P. C. Kurniali, L. G. Luo, and A. B. Weitberg, "Role of calcium/ magnesium infusion in oxaliplatin-based chemotherapy for colorectal cancer patients," Oncology, vol. 24, no. 3, pp. 289-292, 2010.

[31] D. R. Pachman, D. L. Barton, J. C. Watson, and C. L. Loprinzi, "Chemotherapy-induced peripheral neuropathy: prevention and treatment," Clinical Pharmacology and Therapeutics, vol. 90, no. 3, pp. 377-387, 2011.

[32] B. Vincenzi, M. F. Anna, S. Gaia et al., "Identification of clinical predictive factors of oxaliplatin-induced chronic peripheral neuropathy in colorectal cancer patients treated with adjuvant Folfox IV," Supportive Care in Cancer, vol. 21, no. 5, pp. 1313-1319, 2013.

[33] J. M. Schloss, C. Maree, A. Caroline et al., "Nutraceuticals and chemotherapy induced peripheral neuropathy (CIPN): a systematic review," Clinical Nutrition, 2013. 


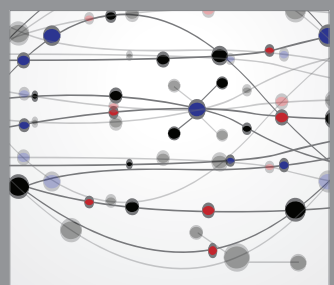

The Scientific World Journal
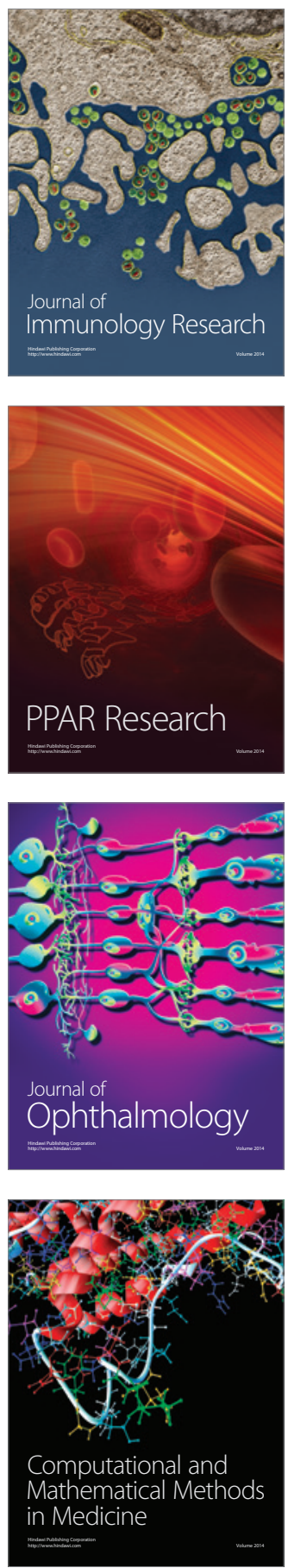

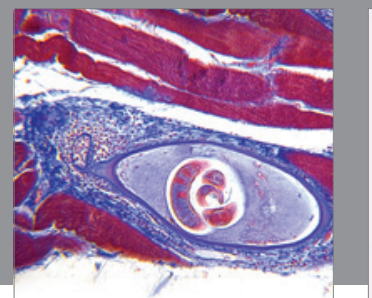

Gastroenterology

Research and Practice
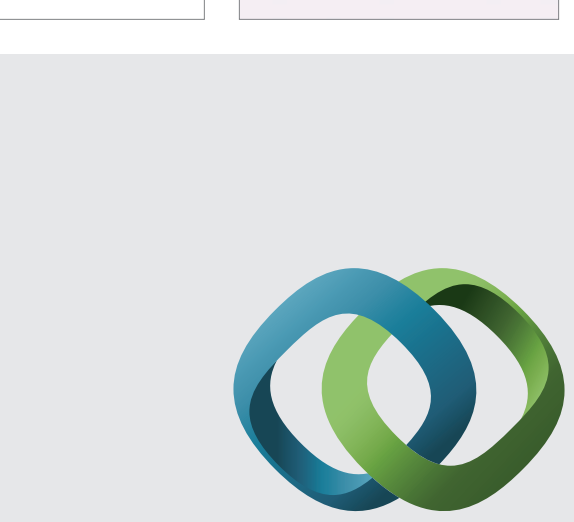

\section{Hindawi}

Submit your manuscripts at

http://www.hindawi.com
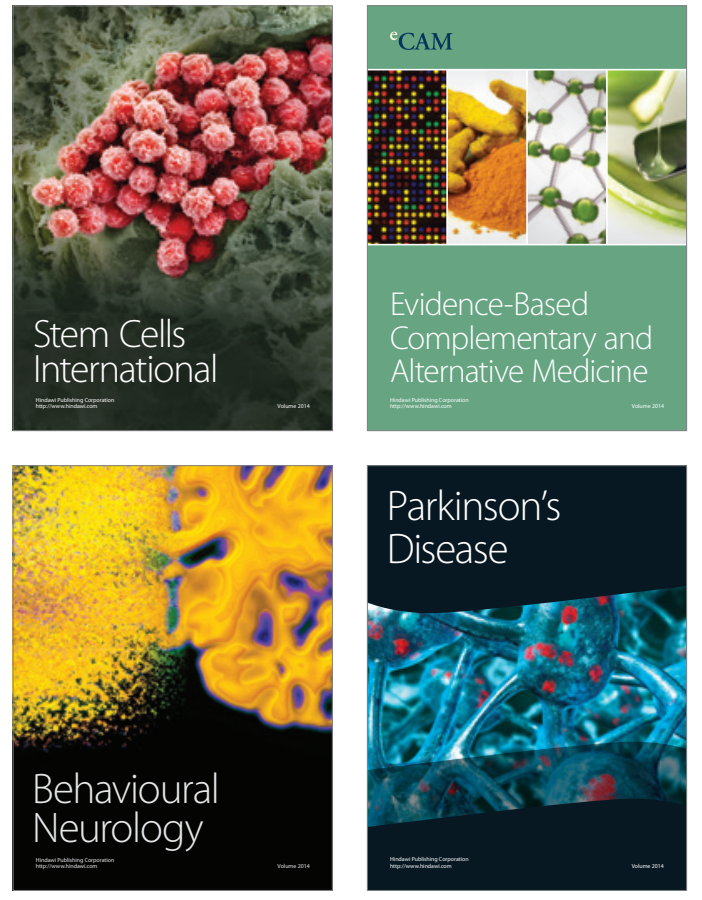
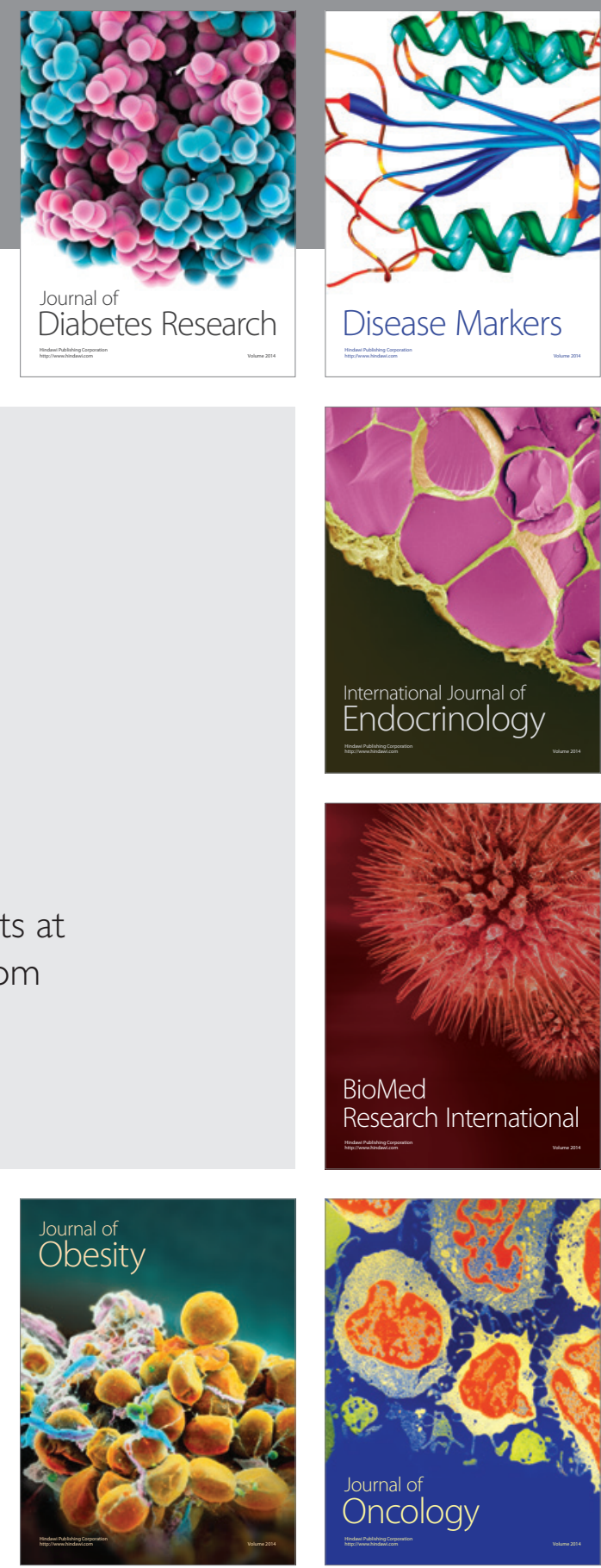

Disease Markers
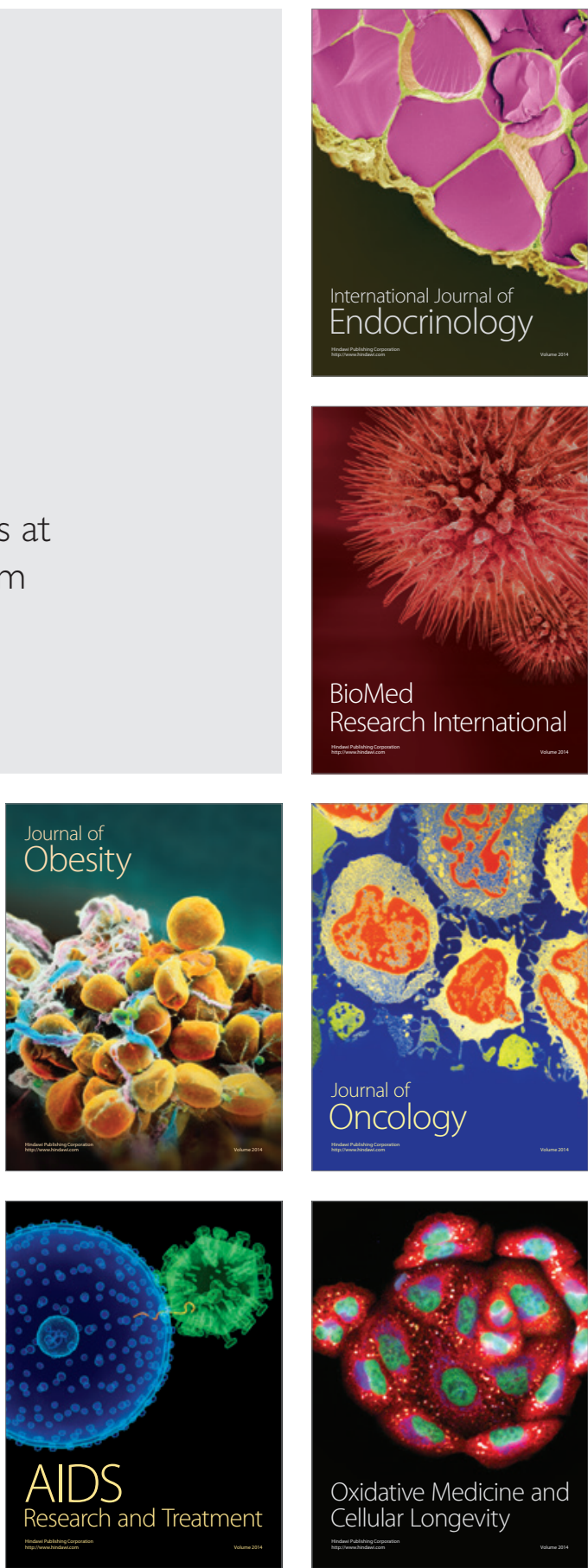